\title{
UTILIZACIÓN DE LAS ENERGÍAS RENOVABLES A NUESTRO ALCANCE PARA PROTEGER EL MEDIO AMBIENTE EN LA PROVINCIA DE HUAURA.
}

\author{
RENEWABLE ENERGY USE OUR BEST TO PROTECT THE ENVIRONMENT IN \\ THE PROVINCE OF HUAURA
}

\author{
Carmen Rosa Aranda Bazalar ${ }^{1}$, Nicanor Darío Aranda Bazalar ${ }^{2}$, \\ Segundo Martínez Namay ${ }^{3}$, Juana Córdova Mattos ${ }^{3}$, Jorge Moreno Jara ${ }^{3}$.
}

\section{RESUMEN}

Objetivo: Implementar las energías renovables para proteger el medio ambiente de la Provincia de Huaura. Material y Métodos: Para los indicadores se aplicó el método científico, observación, diagnóstico, entrevista, encuesta y análisis, se escogió la cuenca baja río Huaura, Sayán y Santa María. Resultados: en el análisis del agua se halló en promedio de demanda bioquímica de oxigeno de $8,4 \mathrm{mg} / 1 ; \mathrm{pH} 8,15$ y $22,5^{\circ} \mathrm{C}$; con presencia de bacterias, hifas, insectos y sustancias extrañas con un caudal de $39,19 \mathrm{~m} 3 / \mathrm{seg}$. La biomasa en los sembríos agrícolas de Sayán, Huaura y Santa María son quemados en un $60 \%$, destinan comida para animales $10 \%$, utilizan abono $15 \%$, reciclan $10 \%$ y venden $5 \%$. Los residuos del área rural son desechados a las acequias y quemados en $100 \%$ y en el área urbana son vendidos a recicladores y el resto llevados a botaderos a cielo abierto. La energía solar está presente en el distrito de Sayán durante todos los meses del año a una temperatura de $26 \mathrm{a} 30^{\circ} \mathrm{C}$. Según la escala de Beaufort la energía eólica y mareomotriz se puede implementar en playa chica y Playa Grande. Conclusión: Existiendo agua, biomasa, energía solar, vientos y mar no se han implementado las energías renovables en la provincia de Huaura y no se está protegiendo el medio ambiente.

Palabras clave: Cuenca; Energía hidráulica; Solar, Eólica; Mareomotriz y Biomasa.

\section{ABSTRACT}

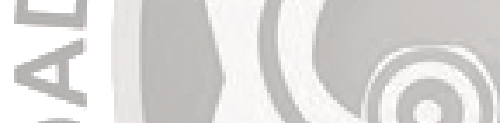

Objective: Implement renewable energy to protect the environment of the Province of Huaura. Materials and MethodsFor the indicators, the scientific method, observation, diagnosis, interview, survey and analysis were applied; the Hüaura river basin, Sayán and Santa María were chosenResultados: in the analysis of water, an average biochemical oxygen demand of $8.4 \mathrm{mg} / 1$ was found; $\mathrm{pH} 8.15$ and $22.5^{\circ} \mathrm{C}$; with presence of bacteria, hyphae, insects and foreign substances with a flow rate of $39.19 \mathrm{~m} 3 / \mathrm{sec}$. The biomass in the agricultural crops of Sayán, Huaura and Santa María are burned by $60 \%$, they allocate food for animals 10\%, use fertilizer $15 \%$, recycle $10 \%$ and sell $5 \%$; The residues of the rural area are discarded to the irrigation ditches and burned in $100 \%$ and in the urban area they are sold to recyclers and the rest taken to open dumps. Solar energy is present in the district of Sayán during all months of the year at a temperature of 26 to $30^{\circ} \mathrm{C}$. According to the Beaufort scale, wind and tidal energy can be implemented in Playa Chica and Playa Grande. Conclusión: Existing water, biomass, solar energy, wind and sea have not been implemented renewable energy in the province of Huaura and is not protecting the environment.

Key words: Basin; Hydropower, Solar; Wind; Tidal and biomass.

\footnotetext{
Docente de la Facultad de Bromatología y Nutrición. Email: caranda@unjfsc.edu.pe

2 Docente de la Facultad de Derecho y Ciencias Políticas

Docente de la Facultad de Educación.
} 


\section{INTRODUCCIÓN}

En la provincia de Huaura contamos con varios problemas que aquejan al sector agricultura, y uno de ellos es la contaminación del agua, suelo, aire y residuos agrícolas. Los estudios nos revelan que los agricultores de la zona queman sus desechos agrícolas contaminando el medio ambiente y esto se agrava aún más con la gran quema de cientos de hectáreas de cañas de azúcares en sus cosechas, produciendo enfermedades alérgicas y bronquiales en la población (Aranda, Infante y Bruno,2006). Las energías renovables son sostenibles si se toman todas las precauciones por ser limpias; por lo que se requiere con urgencia saber cómo se encuentran en la provincia de Huaura estas energías para implementarlas planificando las mejores estrategias. También contamos con el problema de alto consumo de la energía eléctrica en nuestra universidad; pagos muy elevados sin una retribución productiva del uso mismo, rażones más que suficiente que nos con lleva a plantearnos la necesidad de implementar los paneles solares y beneficiar en las prácticas de laboratorio para los estudiantes de la Universidad, y luego pueda ser utilizado por la población e ir disminuyendo sistemáticamente sus gastos de energía eléctrica.

Se desaprovecha los residuos de la agricultura, residuos de la población, aguas de los ríos, aires propicios en nuestra zona, lo que factibilice que realicemos pruebas de implementación de la energía eólica. El mar tiene una energía potencial sin utilizar, por lo que podemos comenzar a realizar estudios de cómo implementar la energía renovable. Es muy benéfico, entonces, tratar las aguas de ríos, regadíos de irrigaciones y tratar los residuos de la ciudad y la agricultura obtendremos la biomasa para utilizarla como energía renovable. El Ministerio de Energía y Minas con la Empresa Privada están utilizando la cuenca alta del río Huaura para implementar energía hidráulica con 158,2 MW al 2014.(Ministerio de Energiay Minas, 2008)

\section{MATERIAL YMÉTODO}

De los 12 distritos de la provincia de Huaura se consideró como muestra a Sayán, Santa María y Huaura. (16, 922 has) y Huacho para deshechos (basura). Se utilizó: material bibliográfico y se aplicó el método científico, Observación, entrevista, encuestas y análisis de Laboratorio.

PROCEDIMIENTO 1.- En los distritos indicados determinar la biomasa que eliminan y la basura de sus localidades de Huaura.- En el distrito de Huaura, la variedad de cultivos están orientados al mercado local, la agroindustria y la agro exportación: destacan por su volumen de producción en hectáreas maíz amarillo duro 2 656, algodón 283; la páprika también es un cultivo de importancia con 37 orientado a la exportación; además, está la producción de camote con 117 , los frijoles con 57 en sus diversas variedades tales como frijol caupi, chiclayo, castilla, chileno, grano seco y grano verde; la papa con 243 . Para el consumo local se produce además ají, ajos, cebolla, col, coliflor, culantro, zanahoria y zapallo; entre las frutas, produce: fresa, lúcuma, manzano, mandarina, mango, maracuyá, melocotones, melón, membrillo, olivo, plátano, sandía y vid. La cantidad de basura que eliminan es $10,000 \mathrm{Kg} /$ diario. El destino es de botadero al cielo abierto $100 \%$ (Aranda y Bruno, 2006). En Huacho se elimina $60000 \mathrm{Kg}$ /diario de basura su destino es botadero a cielo abierto 100\%. En Santa María la producción agrícola es más variada en sus productos, los cuales están orientados al mercado local, la agroindustria y la agro exportación; siendo las hectáreas cultivadas de sus productos más importantes maíz amarillo duro con 225 , zanahoria 53 y maíz chala; resaltan también el cultivo de algodón, arveja grano verde, ajo y paprika; y una gran variedad de frutas tales como: ciruela, chirimoya, guanábana, guayabo, lúcuma, manzano, mandarina, membrillo, naranjo, pacae, y en menor dimensión yuca, tomate. La cantidad de basura que eliminan $10000 \mathrm{Kg}$. /día. El destino de la basura es a cielo abierto $69 \%$, quemada $18 \%$, reciclada $13 \%$. En Sayán la producción agrícola del distrito de Sayán tiene gran variedad de cultivos entre productos orientados al mercado local, la agroindustria y la agro exportación; destacan por su volumen de producción, la caña de azúcar, la producción de variedad de frijoles con cerca de 74 ha para su cultivo, el maíz amarillo duro con 295 ha, el maíz choclo con 682 ha, la páprika para exportación, con $107 \mathrm{ha}$; en cuanto a frutales, destaca la producción de melón, tomate con 46 ha, chirimoya, fresa, limón sutil, lúcuma mango, mandarinas, manzano, maracuyá, melocotones, naranjo, olivo, palto, plátano, papaya, sandia y tangelo. La cantidad de basura que eliminan es de $10000 \mathrm{Kg}$. / día y el destino final es a cielo abierto $100 \%$.

PROCEDIMIENTO 2.- La visita a entidades involucradas se realizó a través de entrevistas quienes no tienen ningún proyecto de energía renovable. Comisión de Regantes; toman acciones para protección del agua de la Cuenca de Huaura 
con la ley 29338 ya pueden utilizar el recurso hídrico. Tienen un proyecto de energía renovable a nivel de perfil en el paraíso y es energía eólica. Ministerio de agricultura, no han realizado ningún proyecto de energía renovable. La Municipalidad no hay proyecto de energía renovable. Las aguas servidas de la provincia de Huaura son descargadas directamente en el mar sin ningún tipo de tratamiento. No tienen proyecto para aplicar las energías renovables.

El Ministerio de Salud supervisa a EMAPA que cumpla con los estándares y control de calidad, es la que realiza el control permanente, cuenta con un laboratorio. No tienen proyectos de energías renovables. Región Lima La central hidroeléctrica de Cheves se ubica en el distrito de Sayán, el proyecto cuenta con estudios preliminares elaborados por la asociación Statkraf Engineering Fichtner en 1998. Actualmente cuenta con la concesión otorgada por el Ministerio de Energía y Minas, y se encuentra en trámite la modificación de la concesión para la reducción de la potencia instalada.

En la propuesta de la modificación se considera una potencia instalada de $158,6 \mathrm{MW}$ que aprovechará las aguas de los ríos Churín y Checras y la inversión estimada alcanza los 134,83 millones de dólares. La fecha prevista para la puesta en servicio es el 2014. Este proyecto se ubica en los distritos de Huacho, Santa María, Sayán, Leoncio Prado y Paccho, el acceso a la zona es a través de la carretera HuauraSayán-Churín-Oyón, cuyo trazo es paralelo al río Huaura.

PROCEDIMIENTO 3.- Lá muestra de agua de la cuenca de Huaura se tomó en Sayán, Santa Rosa, Santa María y Huaura se realizó de acuerdo a las normas de preservación, identificación y almacenamiento de la muestra siguieron los estándares establecidos se observó con el estereoscopio en forma directa, se realizó la técnica de Gram se tomó la muestra extendiéndola en la lamina agregando el cristal violeta esperando un minuto, luego se lavó con agua destilada, agregando lugol esperando un minuto, decolorar con alcohol acetona, lavar con agua destilada y agregar la safranina y se observa al microscopio compuesto. Se utilizó el Oxímetro para determinar la demanda Bioquímica de Oxigeno, la temperatura y con el indicador se determinó el $\mathrm{pH}$.

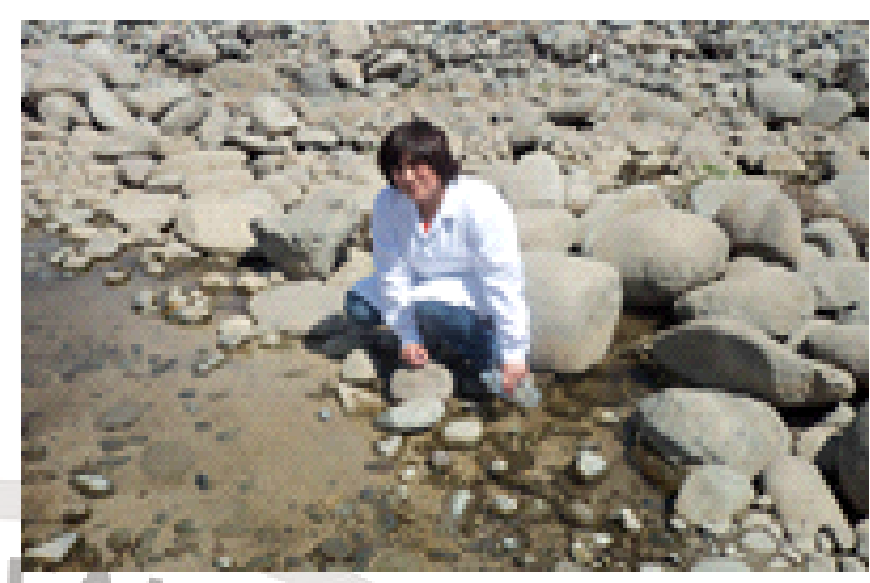

Figura 1. Toma Río Chico.

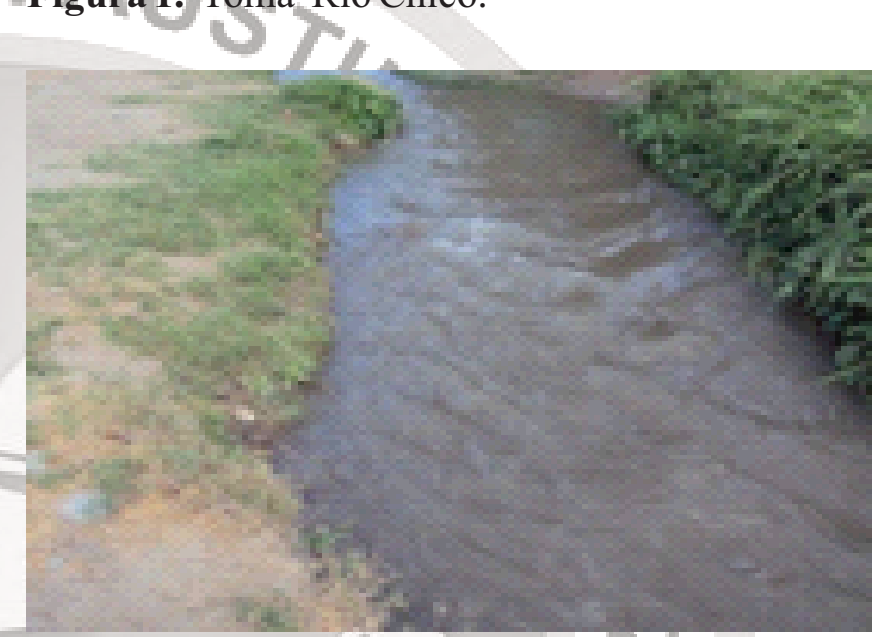

Figura 2. Toma Santá María.

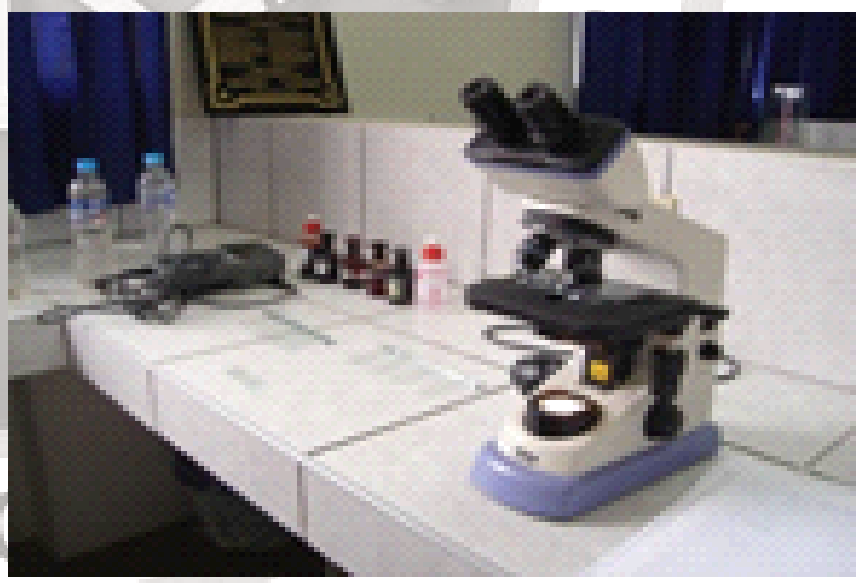

Figura 3. Materiales, equipo y reactivos utilizados

PROCEDIMIENTO 4.- Se analiza los resultados de las aguas para ser utilizadas en energías renovables. La Cuenca de Huaura según Información del 2011-2012. tiene 1'226,866.608 $\mathrm{m} 3 / \mathrm{seg}$, al mes de Julio,y el caudal de 39, $19 \mathrm{~m} 3 / \mathrm{seg}$. 


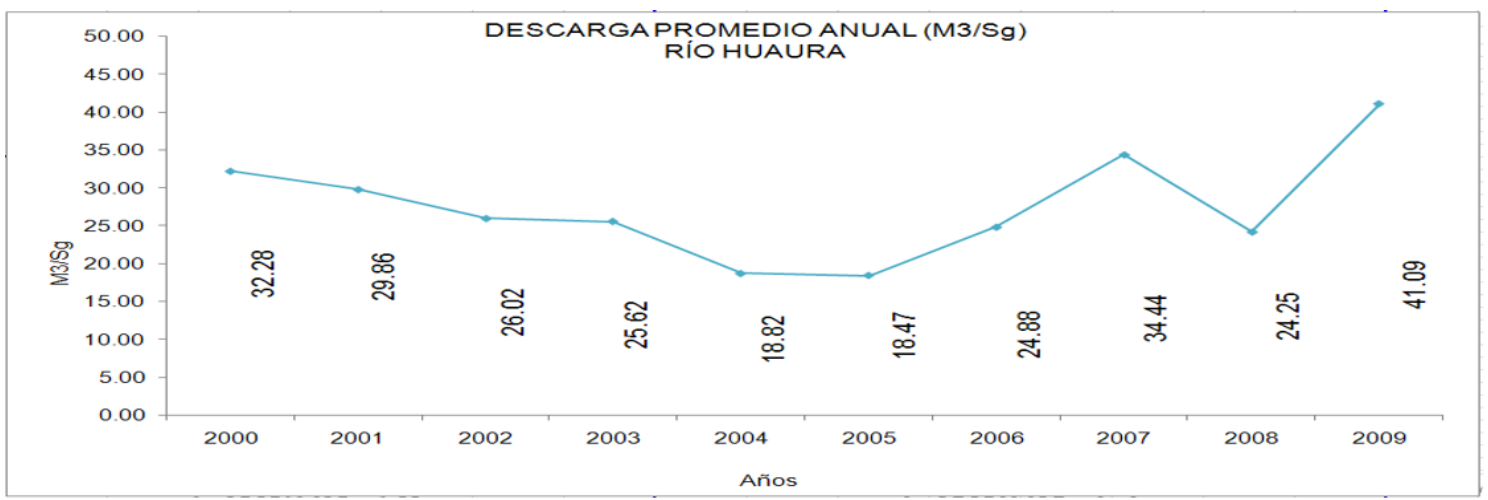

PRODUCTOS DE SEMBRIOS

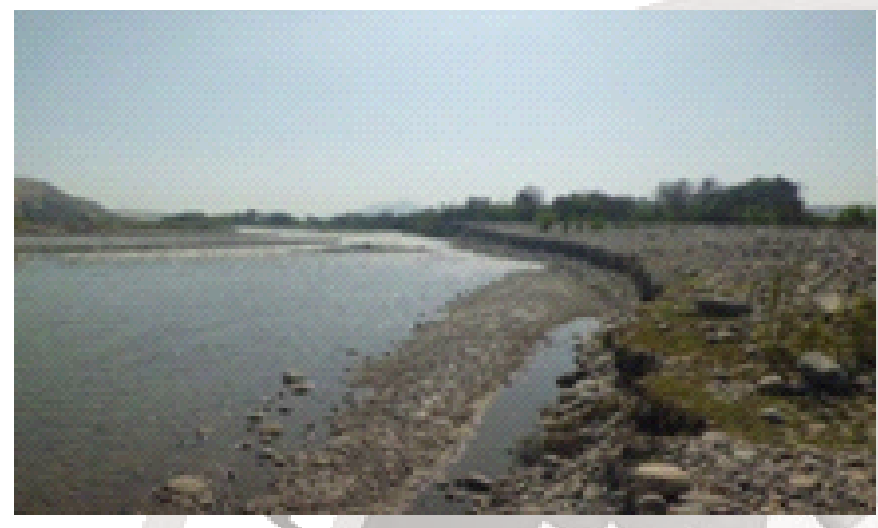

Figura 4. Rio Huaura.

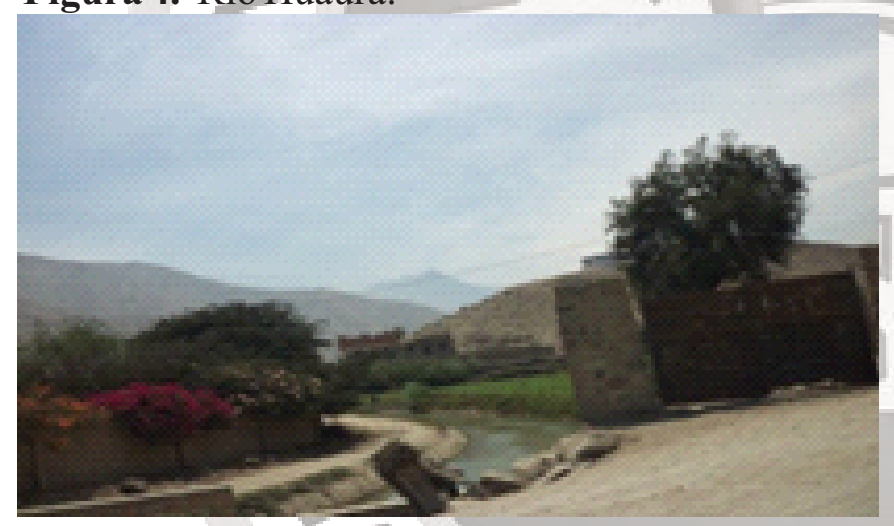

Figura5. Irrigación Santa Rosa.

El rio Huaura tiene una descarga de 15,983.167 m3/seg.; en Sayán, 38, 270,696 m³/seg. Huaura, 15, $983,163 \mathrm{~m}^{3} / \mathrm{seg}$. Santa Rosa $109,710,311 \mathrm{~m}^{3} / \mathrm{seg}$. y la Campiña de Huacho. 6, 320,890 m³ $/ \mathrm{seng}$. Al mes de Julio 2012. Tiene usos domésticos y el $43,2 \%$ cuenta con servicio de agua potable el uso doméstico del agua alcanza a 11.20 millones de $\mathrm{m} 3 /$ año. El uso industrial es 1 '242 $\mathrm{m}^{3} /$ año de la red de suministro público. El uso agrícola es de 719' 082,000 m³/año. El uso minero $986,000 \mathrm{~m}^{3} /$ año.

PROCEDIMIENTO 5.- Se verificó los lugares donde existen desechos orgánicos seleccionado como muestra Huaura, Sayán, Santa María. Realizando el siguiente cuadro.

\begin{tabular}{|c|c|c|c|}
\hline \multicolumn{2}{|c|}{ DISTRITO. PRODUCTOS AGRICOLAS } & \multirow{2}{*}{$\frac{\mathrm{HA}}{283}$} & RESIDUOS. \\
\hline HUAURA. & ALGODÓN & & 576 \\
\hline & CAMOTE & 117 & 117 \\
\hline & MAIZ AMARILLO & 2656 & 13280 \\
\hline & MAIZ CHOCLO & 4 & 20 \\
\hline & PAPA & 243 & 486 \\
\hline & FRUOL GRANO SECO & 57 & 57 \\
\hline & ZANAHORIA & 50 & 50 \\
\hline & CEBOLLA & 24 & 24 \\
\hline & PAPIKRA & 37 & 74 \\
\hline & TOMATE & 44 & 44 \\
\hline & AJOS & 7 & 14 \\
\hline & ZAPALLO & 21 & 21 \\
\hline & ARROZ CON CASCARA & 20 & 20 \\
\hline & ALVERJA GRANO VERDE & 4 & 4 \\
\hline & TOTAL & 3567 & 15576 \\
\hline \multicolumn{2}{|c|}{$\overline{\text { DISTRITO. PRODUCTOS AGRICOLAS }}$} & HA & $\overline{\text { RESIDUOS. }}$ \\
\hline \multirow[t]{14}{*}{ SAYAN } & ALGODON & 5 & 10 \\
\hline & CAMOTE & 3 & 3 \\
\hline & MAIZ AMARILLO & 295 & 1475 \\
\hline & MAIZ CHOCLO & 682 & 3410 \\
\hline & PAPA & 67 & 67 \\
\hline & FRIJOL GRANO SECO & 74 & 74 \\
\hline & CEBOLLA & 27 & 27 \\
\hline & PAPIKRA & 107 & 214 \\
\hline & TOMATE & 46 & 46 \\
\hline & YUCA & 3 & 15 \\
\hline & CEBOLLA BLANCA & 26 & 26 \\
\hline & ALVERJA GRANO VERDE & 18 & 18 \\
\hline & CAN̄A DE AZUCAR & 3473 & 17365 \\
\hline & TOTAL & 5826 & 22730 \\
\hline DISTRITO. & PRODUCTOS AGRICOLAS & $\mathrm{HA}$ & RESIDUOS. \\
\hline \multirow[t]{14}{*}{ SANTA MARIA } & A A.JOS & 15 & 15 \\
\hline & ALGODUN & 11 & 11 \\
\hline & ALVERJA GRANO VERDE & 9 & 9 \\
\hline & CAMOTE & 16 & 16 \\
\hline & FRIJOL GRANO SECO & 12 & 12 \\
\hline & MAIZ AMARILLO DURO & 225 & 1225 \\
\hline & MAIZ CHOCLO & 8 & 40 \\
\hline & PAPA & 9 & 9 \\
\hline & PAPIKRA & 9 & 18 \\
\hline & CEBOLLA BLANCA & 26 & 26 \\
\hline & TOMATE & 17 & 17 \\
\hline & YUCA & 10 & 50 \\
\hline & ZANAHORIA & 53 & 53 \\
\hline & TOTAL & 394 & 1475 \\
\hline
\end{tabular}




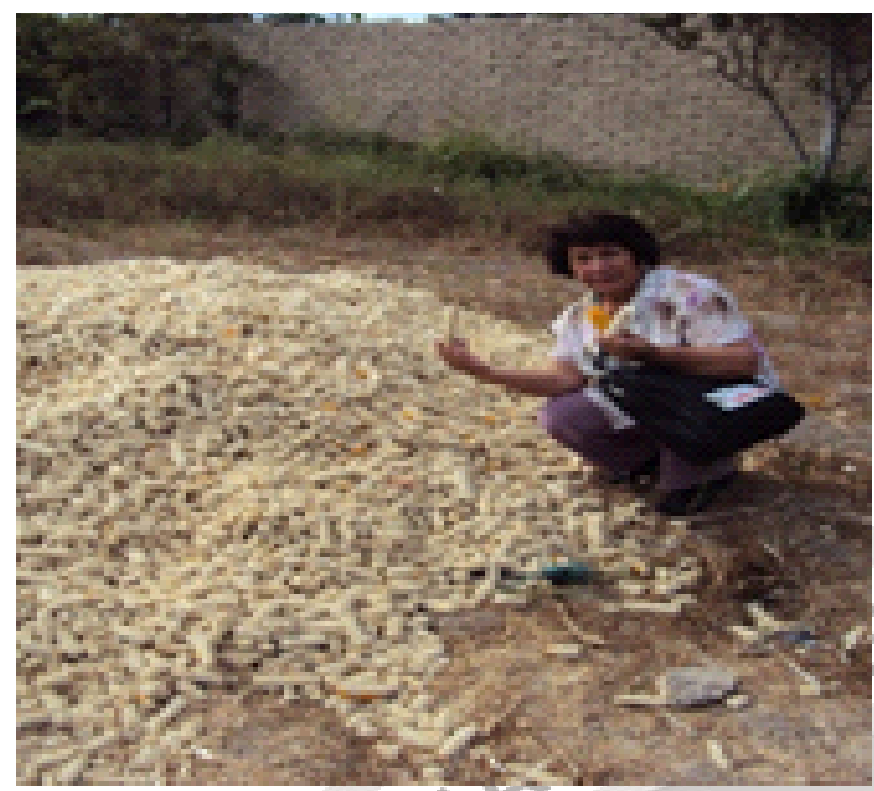

Figura 6. Residuos coronta Sta. María

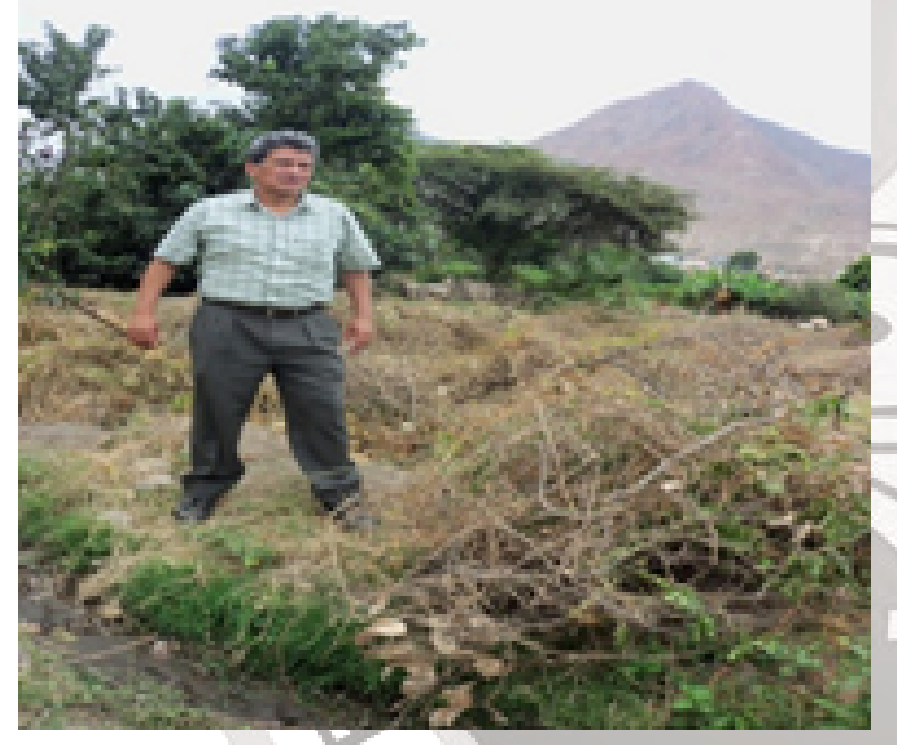

Figura 7. Residuo de maracuyá Sayán

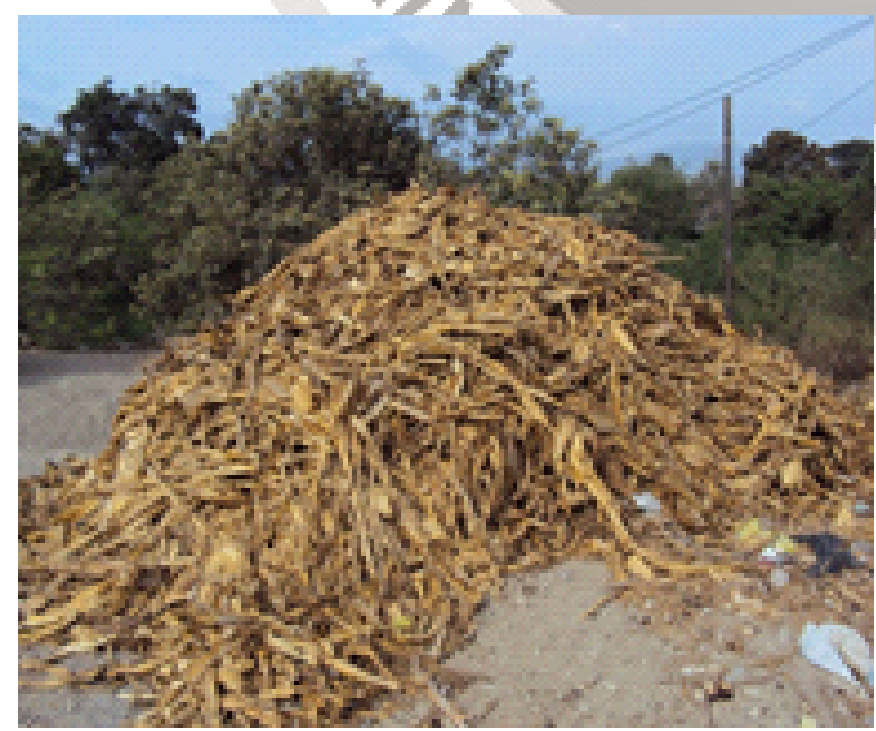

Figura 8. Residuo Maíz.
En la provincia de Huaura, Tenemos 40,305.90 Ha de superficie agrícola en riego se destina el $46 \%$ al cultivo de productos de consumo humano, principalmente en hortalizas, papas, camote, entre otros.

Productos de Consumo Industrial.- Se viene destinando de acuerdo a la proyección destinó para algodón, caña de azúcar, maíz amarillo duro el 36\% de la superficie agrícola.

Productos de agro exportación.- El 6\% de la superficie se destina para este tipo de siembra y tenemos dependiendo del tipo de cultivo el deshecho orgánico, los productos son: Ají, Alcachofa, Espárrago, Chirimoya, Fríjol Castilla, Higuera, Lúcuma, Maíz Morado, Maracuyá, Melocotón, Tuna, Ciruelo, Granadilla, Orégano, Fríjol Vainita, Maca, Mashua, Avena grano.

Pastos de cultivo.- El $12 \%$ de los productos agrícolas son destinados a forraje y alimentación de los productos pecuarios entre ellos se consideran: Alfalfa, Avena Forrajera, Dactylis sp. (pasto ovillo), Maíz Chala.

Se destina el $46 \%$ para la siembra de productos para el consumo humano, el $36 \%$ para el consumo industrial, el $12 \%$ para pastos de cultivo y el $6 \%$ para la agroexportación.

Estos se caracterizan por tener un régimen de escurrimiento irregular y carácter torrentoso, concentrándose las descargas durante 3 ó 4 meses del año de Diciembre a Marzo principalmente, período denominado de avenidas, durante el cual se estima discurre entre el 60 y $70 \%$ de la descarga total anual, teniendo durante el resto del año una baja considerable.

La materia orgánica que nos interesa para nuestro estudio de biomasa es casi quemada por la mayoría de los agricultores.

PROCEDIMIENTO 6.- Residuos de desechos de la basura de los distritos.- Se realizó encuestas, entrevistas y trabajo de campo en el distrito de Huacho se obtiene un promedio de 60 toneladas de basura diarias la cual de cada hogar eliminan de $4 \mathrm{~kg}$. Promedio de basura el $60 \%$ es producto orgánico. Y estos restos se pueden utilizar para la biomasa como energía renovable. \% de basura en Huacho $60 \mathrm{Tm} / \mathrm{d}$, $\%$ de basura orgánica, 40 toneladas/d, \% de basura inorgánica 20 toneladas/d.

PROCEDIMIENTO $\mathbf{N}^{\mathbf{0}}$ 7.- Transformación de la materia orgánica.- Los restos de la agricultura, de los residuos de las ciudades, la materia sólida de los residuos líquidos son materia para la obtención de 
biomasa para obtener las energías renovables $\mathbf{y}$ reutilizar los productos para nutrición de las mismas plantas. Para el área rural se puede concentrar la biomasa en una poza de 3 × 3 metros con una profundidad de 1 metro. Sería en cada casa huerta, agregándole el quelato orgánico, $2 \mathrm{gr} / \mathrm{m} 2$ a base de cobre, para el área urbana se destina un lugar que debe estar ubicado al norte de la ciudad, con 6 pozas consecutivas de $5 \times 5 \times 1 \mathrm{~m}$, de dimensiones. Y aplicarle también el quelato orgánico a base de sulfato de cobre. Para poder utilizar la materia orgánica limpia y libre de microorganismos y poder obtener el gas y materia orgánica para la agricultura libre de organismos contaminantes. Residuos líquidos.- Los residuos sólidos que se asientan en las pozas o tuberías de los desagües y deshechos se pueden utilizar como biomasa gracias a los quelatos que son productos que se agrega a la biomasa y El Cobre Quelatado es un producto que inhibe la acción de las bacterias anaeróbicas y estimula la acción de las bacterias aeróbicas; es un producto realmente efectivo; de bajo costo avalado por organismos reguladores de agua; no es un producto "maravilloso" es realmente un producto revolucionario; tiene más de 20 años ; fue diseñado en Canadá para tratar excretas de puercos en las granjas, luego de varias investigaciones para ver el espectro completo de trabajo del producto se ha aplicado en tratamiento de aguas residuales de manera exitosa.

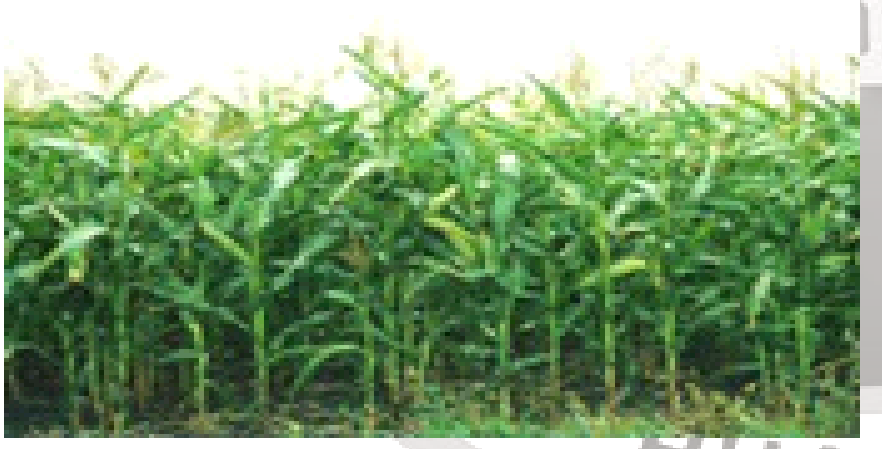

Figura 9. Huaura

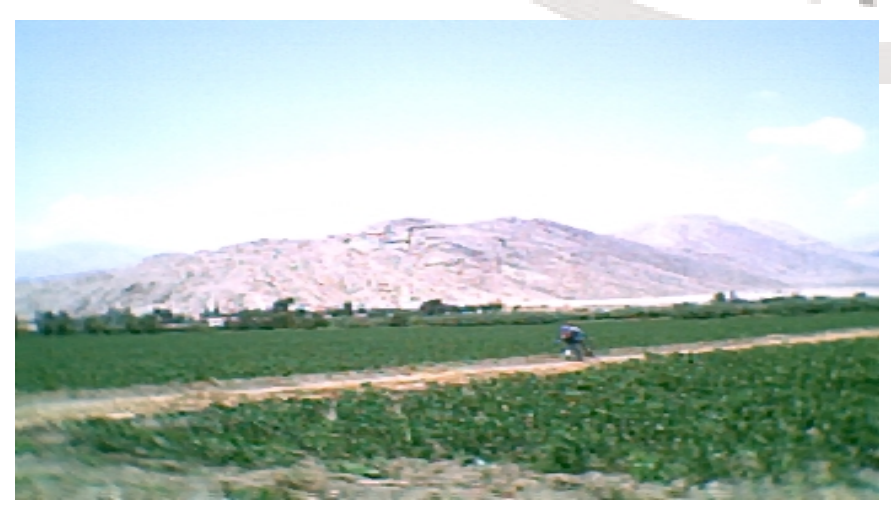

Figura 10. Sayán

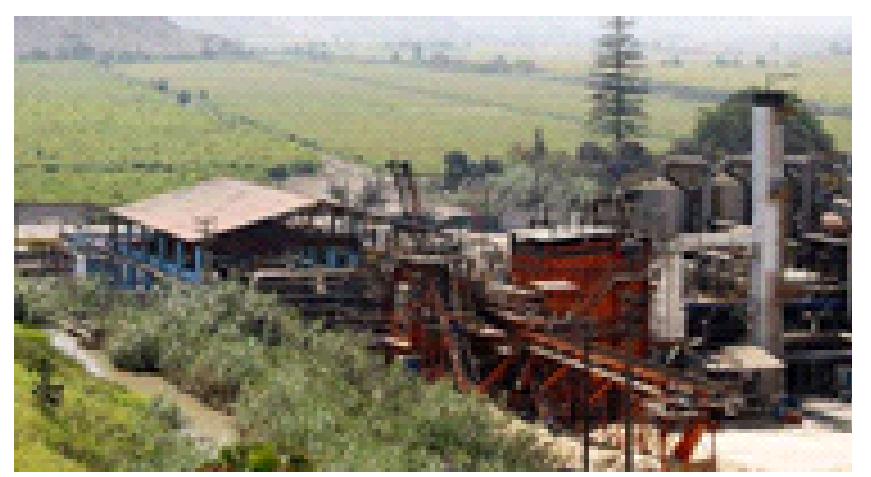

Figura 11. Andahuasi.

PROCEDIMIENTO 8.- Se realiza entrevista y hace trabajo de campo se toma como muestra la Universidad por considerarse un problema el pago mensual de luz de 30000 mensual.

PROCEDIMIENTOS No 9.- Implementación de paneles solares. Mediante la entrevista, trabajo de campo se observó durante diferentes días del año la presencia del sol en los meses de: Abril, Mayo, Junio, Julio, Agosto, Setiembre, Octubre, Noviembre y Diciembre. Con una temperatura de 26 a 30 grados Centígrados y de la entrevista a la población manifiestan que todos los días de cada uno de los meses hay sol.

PROCEDIMIENTO No 10.- Energía Eólica.- Se observó utilizando la escala de Medición de la fuerza del viento según la escala de Beaufort durante los meses de Abril, Agostoy Diciembre el comportamiento del mar de la parte norte considerando Huaura, Carquín y la parte sur Huacho observando:

Huaura.- Escala de Beaufort 3 flojo o pequeña brisa de 7,4 a $12 \mathrm{Km} / \mathrm{h}$.

Carquín.- Escala de Beaufort 4 bonancible o brisa moderada de 20 a $30 \mathrm{Km} / \mathrm{h}$.

Huacho.- Escala de Beaufort 5 fresquito o buena brisa de 31 a $40 \mathrm{Km} / \mathrm{h}$.

Material.- Escritorio, recursos humanos, pasajes, cámara fotográfica.

Método.- entrevista y bibliográfica y de campo

PROCEDIMIENTO No 11.- Implementación de la energía mareomotriz.- Se observó durante los mesesde Abril, Agosto y Diciembre.

Energía gravitatoria terrestre, lunar, solar y eólica dan lugar.

Huaura.- energía gravitatoria presente, lunar presente, solar presente, eólica 3. 
Carquín.- energía gravitatoria presente, lunar presente, solar presente, eólica 4.

Huacho.- energía gravitatoria presente, lunar presente, solar presente, eólica 5.

PROCEDIMIENTO No12.- Implementación de energía Renovables en la Provincia de Huaura.

Según las observaciones realizadas la energía eólica puede ser colocada al sur de Huacho a la altura de la playa Chica ya que los vientos son permanentes durante todos los días del año.

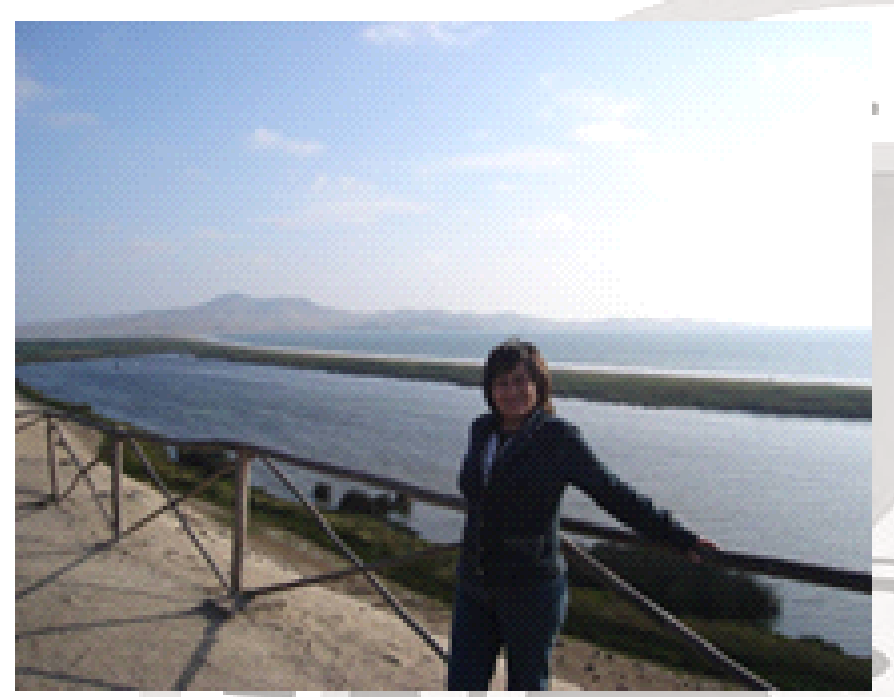

Figura 12. Playa Chica.

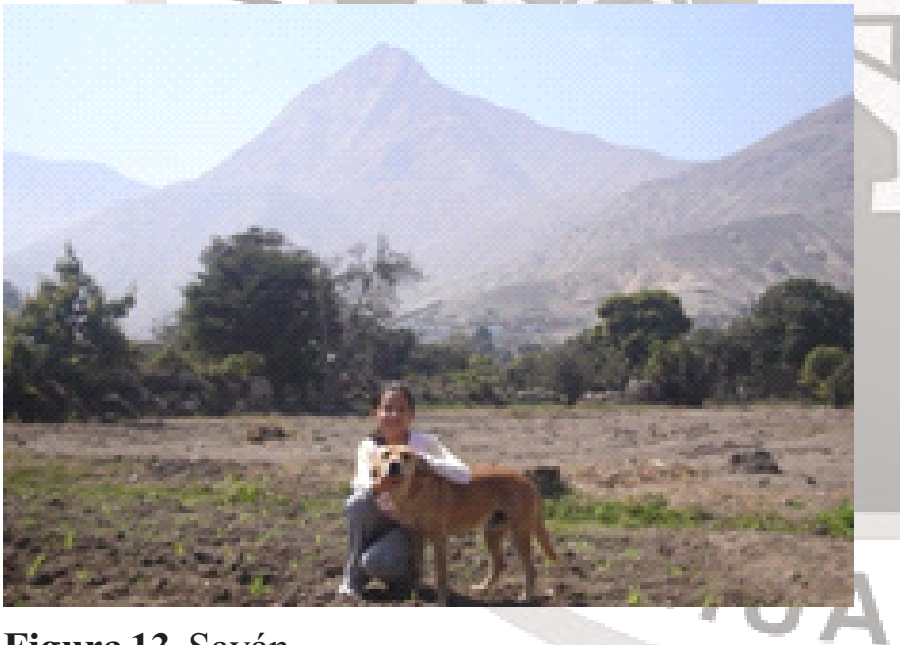

Figura 13. Sayán.

El panel solar puede colocarse en el Distrito de Sayán por haber sol los meses observados de Abril a Diciembre y según los pobladores los 365 días del año. Pero en forma experimental se puede empezar en la Universidad. La biomasa en las áreas rurales en sus propios domicilios, y en las urbanas en la zona Norte de Huacho; y en los lugares donde existan desechos orgánicos, biomasa apropiada para obtener gas ó humus para las zonas más necesitadas, o para enriquecer las tierras.

\section{RESULTADO}

\section{Resultado del diagnóstico de los distritos elegidos.-}

Resultado del procedimiento 1.- En Distrito de Huaura no transforma los residuos sólidos para obtener biomasa. La basura es eliminada a cielo abierto de $10000 \mathrm{Kg} /$ día. El Distrito de Huacho no utiliza los deshechos agrícolas obtener biomasa. Elimina $60000 \mathrm{Kg}$ /diario de basura. Su destino de la basura es botadero a cielo abierto $100 \%$.

Distrito de Santa María. - Si utilizan sus desechos de la agricultura para producir alimento de animales y para abonar sus plantas. La cantidad de basura que eliminan es de $10000 \mathrm{Kg}$./día. El destino de la basura es a cielo abiêrto $69 \%$, quemada $18 \%$, reciclada $13 \%$.

Distrito de Sayán.- Los residuos de la producción agrícola del distrito de Sayán son quemados. La cantidad de basura que elimina es de $10000 \mathrm{Kg}$. /día. El destino final de la basura es a cielo abierto $100 \%$.

\section{Resultados de las entidades involucradas.-} Autoridades Nacionales del Agua

Sí hay acciones para la protección de la Cuenca de Huaura, 2 mega proyectos que están en perfiles; en el congreso se ha aprobado 1000 millones de soles a nivel nacional, a nivel Regional 1/2 millón de soles la ubicación es en Rapaz y Rumbrococha y la cantidad de almacenaje de agua será de 100 millones de m3. Ningún proyecto de energía renovable. Realizan un proyecto de energía hidráulica en coordinación con el ministerio de energía y minas y la Región Lima y la empresa privada con el gobierno central está realizando un proyecto de energía hidráulica que es el proyecto de Cheves. Con una potencia instalada de $158,2 \mathrm{MW}$. y se espera que la operación comercial empiece el 2014. La comisión de regantes toma acciones para protección del agua de la Cuenca de Huaura. Con la ley 29338 ya pueden utilizar el recurso hídrico. Están elaborando un proyecto de energía renovable en el paraíso y es energía eólica.

\section{Municipalidad.-}

No se realizan las acciones para proteger la salud de la población con respecto a los Residuos Líquidos de la población Urbana y rural.

Solo supervisan las acequias y lo demás lo realiza el Ministerio de agricultura. Los ríos lo ven el ministerio de agricultura. No hay proyecto de 


\section{Emapa.}

Las aguas servidas de la provincia de Huaura son descargadas directamente en el mar sin ningún tipo de tratamiento.

\section{Ministerio de agricultura.}

Se encargan de supervisar las aguas, filtraciones, canalizaciones de acequias. El Ministerio de Agricultura en coordinación con la Región Lima y Municipalidad está canalizando muchas acequias y filtraciones estando en el plan de Municipalidades. No han realizado proyectos de energía eólica, paneles solares energía mareomotriz o biomasa.

\section{Ministerio de Salud.-}

Se supervisa a EMAPA que cumpla con los estándares y control de calidad, es la que realiza el control permanente, cuenta con un laboratorio. La calidad de agua de la provincia de Huaura su calificación se encuentra como regular.

\section{Región Lima.-}

No realizan proyectos de energía eólica, paneles solares y mareas. Están elaborando perfiles proyectos para tratar los residuos sólidos de la población.

\section{Resultado de los análisis de muestras.-}

Tabla 1. Resultado del análisis de agua de río con eloxímetro. 2012.

\begin{tabular}{l|l|l|l|l} 
PRUEBAS & HUAURA & $\begin{array}{l}\text { SANTA } \\
\text { MARIA }\end{array}$ & SAYÁN & $\begin{array}{l}\text { SANTA } \\
\text { ROSA }\end{array}$ \\
\hline DBO (MGIL) & 8,4 & 8,2 & 7,7 & 8,4 \\
$\mathrm{pH}$ & 8 & 8,3 & 8 & 8,3 \\
$\mathrm{~T}^{\circ}$ & 23,1 & $23,2^{\circ}$ & $21^{\circ}$ & $23,2^{\circ}$ \\
\hline
\end{tabular}

Tabla 2. Observación al estetoscopio.

\begin{tabular}{|c|c|c|c|c|}
\hline OBSERVACIÓN & HUAURA & SANTA MARI A & SAYÁN & SANTA ROSA \\
\hline HIFAS & + & + & + & + \\
\hline INSECTOS & + & + & + & + \\
\hline SUSTANCIAS & + & + & + & + \\
\hline EXTRAÑAS. & & & & \\
\hline
\end{tabular}

Tabla 3. Observación al microscopio ténica de gram.

\begin{tabular}{llrrr}
\hline MUESTRA DE AGUA HUAURA & SANTA MARI A & SAYÁN & SANTA ROSA \\
\hline TÉCNICA GRAM & Presencia de & Presencia de & Presencia de & Presencia de \\
& Bacterias. & Bacterias. & Bacterias. & Bacterias. \\
\hline
\end{tabular}

Resultado de las aguas para ser utilizadas en energías renovables.-

El rio Huaura tiene un caudal de $27,12 \mathrm{~m}^{3} / \mathrm{seg}$ volumen promedio anual, esto representa 855,84 millones de metros cúbicos.

Verificación de los lugares donde existen los desechos. Verificar los resultados sólidos en la provincia de Huaura. Verificar los costos de alumbrado. Ver lugares para implementación de Energía.

Las zonas que poseen más desechos orgánicos son tos que se dedican a la agricultura, Sayán, Huaura, Santa María. En la provincia de Huaura, Tenemos 40,305.90 Has de superficie agrícola en riego se destinado el $46 \%$ al cultivo de productos de consumo humano, principalmente en hortalizas, papas, camote, entre otros. En los distritos de Sayán, Santa María y Huaura de 9787 ha de diversos sembríos se obtiene la cantidad de 39 871Tm de biomasa.

Residuos de deshechos de la basura de los distritos.-

En el distrito de Huacho, Sayán, Huaura, Santa María; Las municipalidades venden a los recicladores y el resto van a los botaderos a cielo abierto en Huacho, Huaura, Sayán, Santa María. Suman en total $90000 \mathrm{Tm}$ de Basura diaria

\section{Alumbrado eléctrico en la universidad.-}

Uno de los problemas que existe en nuestra universidad es el costo elevado de luz se paga aproximadamente 30,000 nuevos soles mensual.

\section{Implementación de paneles solares.}

Presencia de sol en Sayán durante los meses: Abril, Mayo, Junio, Julio, Agosto, Setiembre, Octubre, Noviembre y Diciembre con una temperatura de 28 a 30 grados centígrados. 


\section{Implementación de la energía mareomotriz.-}

De acuerdo a la observación durante los meses de Abril, Agosto y Diciembre.

Dan lugar a la energía gravitatoria terrestre, lunar, solar y eólica.

Huaura.- energía gravitatoria presente, lunar presente, solar presente, eólica 3.

Carquín.- energía gravitatoria presente, lunar presente, solar presente, eólica 4.

Huacho.- energía gravitatoria presente, lunar presente, solar presente, eólica 5.

No está considerado como proyecto en la región Lima ni en la Provincia de Huaura. Pero según los estudios se pueden implementar en playa chica o playa grande.

\section{Implementación de energías renovables en la provincia de Huaura.}

La energía eólica puede ser colocada al sur de Huacho a la altura de la playa Chica ya que los vientos son permanentes durante todos los días del año. El panel solar puede colocarse en el Distrito de Sayán por haber sol los 365 días del año. Se puede empezar la experimentación por la zona de rio chico, Huamilanchi ya que contiene los lugares apropiados y esa zona no cuenta con luz eléctrica es una zona rural importante. Pero en forma experimental se puede empezar en la Universidad, siendo aprovechado para las prácticas de los estudiantes de las escuelas de Ciencias, Ingeniería y Matemática Física e Informática y Biología Química y Tecnología de los Alimentos de la Facultad de Educación.

\section{DISCUSIÓN:}

Distrito de Huaura, Santa María y Sayán, No utilizan los residuos de las cosechas para obtener biomasa pero lo queman y sabemos que esto produce enfermedades en la población1. La basura es eliminada a cielo abierto $90000 \mathrm{Kg}$ /día en los diferentes distritos. Este residuo puede utilizarse para generar energía como se hace en otros países de Europa y América del norte y algunos de Sudamérica. Las entidades involucradas no están implementando las energías renovables salvo 2 proyectos en perfiles uno para comisión de regantes energía eólica y otro la municipalidad para tratar sus residuos líquidos. Es penoso observar mientras otros países implementar al $20 \%$ s u s n e cesidad e s e nergé ti cas.. Las autoridades involucradas Región Lima, Municipalidad, Ministerio de agricultura, Emapa,
Ministerio de Salud no implementan las energías renovables en la provincia de Huaura. El Ministerio de Energía y Minas con la empresa privada elabora el proyecto de energía hidráulica proyecto de chevés que es un proyecto que funcionará el 2014 con 158,2 Mw7.

Los resultados de los análisis de las aguas de la Cuenca de Huaura realizado por el Servicio Nacional de Meteorología e hidrología muestra presencia de coliformes totales pasando los LMP; un $\mathrm{pH} 8,24,23,6 \mathrm{~T}^{\circ} \mathrm{C}$, DBO $7 \mathrm{mg} / \mathrm{L}$ y los resultados de la calidad del agua se halló en promedio de demanda bioquímica de oxigeno de $8,4 \mathrm{mg} / \mathrm{l} ; \mathrm{pH}$ 8,15 y $22,5^{\circ} \mathrm{C}$; con presencia de bacterias, hifas, insectos y sustancias extrañas. Estos resultados nos indican que las aguas están contaminadas contaminando la biomas de los sembríos agrícolas.

\section{Discusión de las aguas para ser utilizadas en energías renovables}

El rio Huaura tiene un caudal de $27.12 \mathrm{~m} 3 / \mathrm{seg}$ volumen promedio anual, esto representa 855.84 millones de metros cúbicos. Con esta cantidad de agua se produce en otros lugares sistemas hidráulicos pequeños para satisfacer la necesidad de la población urbana y rural, sin embargo en nuestra provincia no se está aprovechando este caudal de agua para obtener energías.

La Información del 2011-2012.- 1'226,866.608 $\mathrm{m} 3 / \mathrm{seg}$, al mes de julio. caudal de $39.19 \mathrm{~m} 3 / \mathrm{seg}$. En la cuenca de Huaura se incrementa el agua teniendo que tomar medidas para utilizarla adecuadamente generando energía sana.

Las zonas que poseen más desechos orgánicos son los que se dedican a la agricultura Huaura, Sayán (Andahuasí, Santa Rosa), Santa María. La biomasa de diversos sembríos de 9787 has se obtiene la cantidad de $39871 \mathrm{Tm}$ de biomasa. La caña de azúcar gran cantidad de materia orgánica, todos estos restos de la agricultura sirven como biomasa para obtener energía renovable, pero no se utiliza para ello sino se quema contaminando el medio ambiente. provincia de Huaura, Tenemos 40,305.90 has de superficie agrícola en riego se han destinado el $46 \%$ al cultivo de productos de consumo humano, principalmente en hortalizas, papas, camote, entre otros, imaginen el potencial de residuos de biomasa para ser usado como nutrientes para las plantas, sin embargo son quemados; mientras que en otros países son utilizados para humus, electricidad, gas.

Transformación de la materia orgánica.Transformación de la materia orgánica en su mayoría los agricultores de Sayán, Santa María, y 
Huaura queman sus restos de sus cosechas por temor a contaminación de las tierras por enfermedades y plagas, por desconocimiento.

Residuos líquidos que se asientan en las pozas o tuberías de los desagües y deshechos se van a los ríos, acequias y mar contaminando todas las riveras.

En el Distrito de Huacho tenemos concentrada la mayor cantidad de Residuos $60 \mathrm{Tm}$ de basura y 40 Tm es basura orgánica y $20 \%$ es inorgánica. Los residuos de las ciudades, las municipalidades venden a los recicladores y el resto los votan a los botaderos a cielo abierto en Huacho, Huaura, y Santa María, contaminando la ciudad de Huacho y los distritos. Pudiendo utilizar 90 toneladas de basura para ser transformada en electricidad para pueblos del área rural y biomasa para utilizarlo para la agricultura.

Alumbrado eléctrico en la universidad.-

Uno de los problemas que existe en nuestra universidad es el costo elevado de luz se paga aproximadamente de 30000 nuevos soles mensual de luz, lo que nos lleva a tratar de buscar solución. En Chile, Colombia y Brasil, EEUU en las casas tienen energía mixta, contando con sus paneles solares.

\section{Implementación de paneles solares.}

Hay dos formas de usar la energía que viene del sol: recogiendo su calor (energía solar térmica) o convirtiendo su luz en electricidad (Energía Fotovoltaica).

En Sayán, Humaya, Andahuasi, Santa Rosa, Quintay, se puedeimplementar los paneles solares y utilizarlos para satisfacer las necesidades eléctricas de las áreas rurales. E1 futuro solar peruano dependerá como en otros ámbitos de nuestras capacidades de la claridad de nuestras ideas y el objetivo generar el desarrollo sostenible dê nuestros pueblos. Empresas privadas han alcanzado un proyecto al ministerio de energía y minas que el estudio realizado en la costa peruana es propicio para la implementación de la energía solar.

\section{Implementación de la energía mareomotriz.-}

No esta considerado como proyecto en la región Lima ni en la Provincia de Huaura. Pero según los estudios se pueden implementar en playa chica o playa grande, y el estado, y empresa privada y la Universidad pueden empezar este proyecto previniendo las catástrofes naturales, que predicen los estudiosos del ambiente.
La energía mareomotriz genera una fuerte inversión de dinero, pero con ayuda del estado se puede implementar, sobre todo cuando sabemos que vienen catástrofes naturales que tenemos que prepararnos para abaratar los costos de energía y utilizar la materia prima energía que son los movimientos del mar. $\mathrm{Y}$ vemos el costo de instalación de generación por mareas u olas, y el costo de instalación por generación de corrientes marinas.

La energía gravitatoria terrestre y lunar la energía solar y la eólica dan lugar respectivamente a 3 manifestaciones de la energía del mar: las mareas, gradientes térmicos y olas y es lo que tenernos en el mar de Huacho, y lo que se tendría que aprovechar embalsando agua de mar en ensenadas naturales y haciéndola pasar a través de turbinas hidráulicas.

\section{CONCLUSIONES}

Al analizar el agua de los ríos se encuentra en una Demanda Bioquímica de oxigeno promedio de $8,175 \mathrm{mglL}$,cumple con el rango que establece la legislación nacional (categoría 3) para bebida de animales y riego de vegetales (entre 6,5 mglL y 8,5 $\mathrm{mglL}$ ). Pudiendo utilizarse como pequeñas plantas energía hidráulica para las áreas urbanas y rurales. Las Aguas de ríos, regadíos de irrigaciones se encuentran contaminadas con presencia de bacterias, protozoos y parásitos. Por los deshechos que vierten las ciudades, industrias. La contaminación del agua perjudica la materia orgánica de los sembríos agrícolas. Los residuos de los sembríos agrícolas se queman en un $60 \%$, destinan a comida de animales $10 \%$, lo utiliza para abono $15 \%$, recicla $10 \%$ y lo venden $5 \%$. Los residuos sólidos de área rural y urbana van a las acequias y quemados $100 \% \mathrm{y}$ en el área urbana son vendidos a recicladores y el resto ubicados en botaderos a cielo abierto.

De acuerdo a las observaciones realizadas el mejor lugar para implementar los paneles solares es el Distrito de Sayán y podrían ahorrar la mitad de su consumo de pago de luz; las áreas rurales implementar su energía eléctrica; y en la Universidad se pueden implementar para práctica con los estudiantes de diferentes especialidades y disminuir los costos de gastos de energía. De acuerdo a las observaciones realizadas el lugar para implementar la energía eólica es playa chica o playa grande y la energía de las mareas se pueden implementar en playa grande como centro experimental. No se están implementando las energías renovables biomasa, solar, eólica 
mareomotriz en la provincia de Huaura; Por lo que no se esta protegiendo el medio ambiente y no se està beneficiando a la población ni a su salud. Beneficios protección del medio ambiente, se darán en el abaratamiento de la energía eléctrica, abastecimiento sin cortes a la población, disminución de la contaminación ambiental. No se esta preparando pequeñas plantas hidráulicas, utilizando la basura de la población, la biomasa de los residuos líquidos, biomasa en la agricultura para obtener energías renovables que sirven tanto a los lugares urbanos y rurales para obtener energía limpia y abaratar los costos de energía eléctrica, gas y humus.

\section{AGRADECIMIENTO}

Se agradece a la comisión de regantes de la Cuenca de Huaura, Municipalidad de la Provincia, al Ministerio de Agricultura, Emapa, Ministerio de Salud, Región Lima, por su información. A los Agricultores, al Jefe y asistente del laboratorio de Biología de la Facultad de Educación.

\section{REFERENCIA BIBLIOGRAFICAS}

Aranda C. Infante H, Bruno C. Procesamiento de la basura para la protección del medio ambiente y promoción del eco turismo en la provincias de Huaura, Barranca y Huaral. Región Lima. Huacho. UNJFSC Perú. 2006.

Aranda C. Infante H, Bruno C. La Provincia de Huaura como modelo Experimental par la instalación de una planta de reciclaje de basura organizar para la obtención de metano y la protección del medio ambiente. UNJFSC. Huacho. Perú. 2006.

Ley de Recursos Hídrico. Ley N²9338. Resolución jefatura N²91-2009-ANA. Lima Perú. 2009.

MINISTERIO DE ENERGÍA Y MINAS. Estudio del plan Maestro de Electrificación Rural con Energía Renovable en la República del Perú (estudio realizado por la Agencia de Cooperación Internacional de Japón). Perú 2009

\section{HUACHO}

